\title{
La resonancia sería más útil que la tomografía en el diagnóstico de accidente cerebrovascular
}

\author{
Magnetic resonance could be more useful than tomography in the diagnosis of stroke
}

Lancet. 2007; 369: 293-8

\section{Objetivo}

Comparar la eficacia de la tomografía axial computada (TAC) y la resonancia nuclear magnética (RNM) los pacientes con accidente cerebro vascular (ACV).

\section{Diseño}

Estudio prospectivo y ciego.

\section{Lugar}

Hospital suburbano, Bethesda, Maryland, EEUU.

\section{Pacientes}

356 pacientes consecutivos admitidos en un único centro $(217$ con diagnóstico final de ACV) con un promedio de edad de 76 años (rango 21-100) un tiempo desde el inicio de los síntomas a la realización de la RNM de 367 minutos, y a la de la TAC, de 390 minutos.

\section{Descripción de los tests}

Se realizaron RNM y TAC (ambas sin contraste y en ese orden) con un lapso entre ambas menor a 120 minutos. Las imágenes fueron analizadas en forma independiente por dos neuroradiólogos y dos neurólogos especializados en ACV con desconocimiento de la clínica y del resultado del otro examen.

\section{Medición de resultados principales}

Sensibilidad, especificidad y grado de acuerdo entre la TAC y RNM y en relación al diagnóstico clínico final.

\section{Resultados principales}

ACV isquémico agudo: la sensibilidad de la RNM fue $83 \%$ (IC95\% 77-88\%) y tuvo una tasa de falsos negativos del $17 \%$ (IC95\% 12-24\%). La TAC tuvo una sensibilidad del $26 \%$ (IC95\% 20-32\%).

ACV hemorrágico agudo: la RNM tuvo una sensibilidad de $81 \%$ (IC95\% 61-93\%) y una especificidad de 100\% (IC95\% 98$100 \%$ ). La TAC tuvo una sensibilidad de $89 \%$ (IC95\% 70-97\%) y una especificidad de 100\% (IC95\% 98-100\%).

En relación al diagnóstico clínico final de ACV agudo la RNM tuvo un acuerdo de $89 \%$ (IC95\% $85-92 \%$ ) y la TAC de $54 \%$ (IC95\% 49-59\%). La sensibilidad de la RNM disminuyó a medida que se acortaba el intervalo desde el inicio de los síntomas. Las causas principales de fallo en el diagnóstico de ACV agudo correspondieron a localización troncal de la lesión, un inicio menor a tres horas y un puntaje menor a cuatro en la Escala del National Institute of Health para ACV.

\section{Conclusiones}

La RNM es mejor que la TAC en la detección de lesiones isquémicas agudas y puede detectar lesiones hemorrágicas agudas y crónicas.

Palabras claves: Accidente cerebrovascular, tomografía axial computada, resonancia nuclear magnética.

Key words: Cerebrovascular accident, computed tomography, magnetic resonance. Key words: Cerebrovascular accident, computed tomography, magnetic resonance
Fuente de financiamiento: National Institute of Health, National Institute of Neurological Disorders and Stroke, Bethesda, MD, USA.

\section{Comentario}

Tradicionalmente se utilizó la TAC para el reconocimiento de las hemorragias intracraneales y por ello fue empleada para el rastreo de hematomas o para decidir iniciar tratamiento trombolítico. La RNM ya se consideraba más sensible que la TAC no contrastada en el reconocimiento de lesiones isquémicas, y esto se incrementó desde la aplicación de técnicas de difusión, sin embargo existían dudas sobre su capacidad para identificar focos hemorrágicos. Varios trabajos previos se han ocupado de mostrar que la RNM es al menos tan confiable como la TAC en este particular ${ }^{1,2}$, coincidentemente con los resultados del presente estudio, aún a pesar que la RNM había sido realizada previamente a la TAC.

Debe tenerse en cuenta que el conocimiento por parte del radiólogo del cuadro clínico del paciente habitualmente mejora el desempeño de ambos métodos, al igual que el uso de la TAC contrastada con técnicas angiográficas y de perfusión y que solo con este estudio puede reconocerse el área de "penumbra" correspondiente al tejido que estaría en condiciones de tratarse y recuperarse.
Este trabajo establece que la TAC sin contraste no se justifica para el diagnóstico clínico de ACV y sugiere que, desde el punto de vista financiero y logístico, tampoco parece justificado el uso de la TAC en centros donde se cuente con RNM. De todos modos recordamos que las lesiones en el tronco son aun críticas, puesto que la difusión puede fallar en demostrar los cambios por el movimiento del agua o pueden aparecer artefactos que dificulten la interpretación de las imágenes

\section{Conclusiones del comentador}

El uso de la RNM sería más beneficioso que la TAC en casos de ACV agudo ya que aquella se encuentra en mejores condiciones de demostrar diferencias entre el tejido normal y el afectado por isquemia dado que reconoce más fácilmente el edema que acompaña al ACV. Alejandro J. Rasumoff [ Servicio de Diagnóstico por Imágenes. Hospital Italiano de Buenos Aires. ]

Ver glosario*

Rasumoff AJ. La resonancia sería más útil que la tomografía en el diagnóstico de accidente cerebrovascular. Evid. actual. práct. ambul; 10(3): 75. MayJun 2007. Comentado de: Chalela JA, et. al. Magnetic resonance imaging and computed tomography in emergency assessment of patients with suspected acute stroke: a prospective comparison. Lancet. 2007 Jan 27; 369(9558): 293-8. PMID: 17258669

\section{Referencias}

1. Viswanathan A, Chabriat H. Cerebral microhemorrhage. Stroke. 2006 Feb;37(2):550-5.

2. Srinivasan A, Goyal M, Al Azri F, Lum C. State-of-the-art imaging of acute stroke. Radiographics. 2006 Oct; 26 Suppl 1:S75-95. 